\title{
Reach of "VAMOS" program in basic healthcare - organizational barriers and facilitators
}

\author{
Rossana Arruda Borges' (D) \\ Camila Tomicki2 ${ }^{\mathbb{D}}$ \\ Fabio Araujo Almeida ${ }^{3}$ (D) \\ Andiara Schwinge ${ }^{4}$ ID \\ Wojtek Chodzko-Zajk0 4 ID \\ Tânia Rosane Bertoldo Benedetti² ${ }^{(D)}$
}

\section{Abstract}

Objective: To investigate the organizational barriers and facilitators to the reach of the "Active Life Health Improvement Program" (or VAMOS) implemented in two Basic Health Units (BHU) in Santa Catarina, Brazil. Method: An experimental study was carried out, based on the RE-AIM framework (http://www.re-aim.org/). Barriers and facilitators were identified through a focus group, semi-structured interview and content analysis. Results: In terms of reach, of the 297 Basic Health Care (BHC) users from the two BHU, 51 elderly people participated, a rate of $17.2 \%$. One notable barrier identified was the lack of support from health teams, while the recommendation of the program by health professionals was found to be a facilitator. Conclusion: The VAMOS program has the potential to be incorporated as a public policy in the process of health care and promotion in BHC. It is an unprecedented strategy in Brazil, aimed at behavioral change, using a sustainable system, the BHU, which has a considerable population reach.

1 Prefeitura Municipal de Recife, Programa Academia da Cidade. Recife, Pernambuco, Brasil.

2 Universidade Federal de Santa Catarina, Programa de Pós-Graduação em Educação Física. Florianópolis, Santa Catarina, Brasil.

3 University of Nebraska Medical Center, College of Public Health, Department of Health Promotion, Social, and Behavioral Health. Omaha, Nebraska, Estados Unidos.

4 University of Illinois at Urbana-Champaign, Department of Kinesiology and Community Health. Champaign, Illinois, Estados Unidos.

Financing: Lemann Institute for Brazilian Studies, 12 março de 2013 e Conselho Nacional de Desenvolvimento Científico e Tecnológico (CNPq). Edital Universal processo n.475.075/2012 -9.

Correspondence

Rossana Arruda Borges

Received: December 07, 2018

rab_ametista@hotmail.com
Keywords: Program Evaluation. Primary Health Care. Healthy Lifestyle.

Health of the Elderly. 


\section{INTRODUCTION}

The prevalence of physical inactivity is high throughout world, including in Brazil ${ }^{1,2}$. It is considered one of the four risk factors for the development of chronic non-communicable diseases ${ }^{2}$. At the same time, physical activity is widely publicized as being beneficial to health. Such evidence is already established in literature ${ }^{3}$. Yet promoting physical activity at the population level is still a challenge $e^{4}$.

In Brazil, the Ministry of Health has been investing resources in implementing physical activity programs in the Unified Health System (or SUS) ${ }^{5,6}$ since 2005. In 2006, the National Policy for Health Promotion (or PNPS) was approved, which inserted physical activity into the health promotion strategy, and reinforced the importance of promoting a physically active lifestyle ${ }^{6}$.

As part of this process, there has been an increase in the provision of traditional physical activity programs throughout Brazil. In general, these programs are characterized by the presence of a Physical Education professional and structured classes (aerobics, yoga, and dance, among others), with a weekly duration of two to three hours. This type of program has achieved good results when the group is assiduous and perform the activities with moderate intensity ${ }^{7-11}$. However, they are expensive for the SUS to maintain as they require appropriate spaces, specific materials and a large number of professionals, and also serve a restricted public and have low population reach ${ }^{12}$.

In this context, a program of behavioral change was created, called the Active Life Health Improvement Program (or VAMOS), based on the social-cognitive theory of Albert Bandura ${ }^{13}$, which aims to motivate people to adopt an active and healthy lifestyle through physical activity and eating habits ${ }^{14,15}$. It aims to remedy the gaps in current traditional physical activity programs, with a view to increasing the adhesion of participants and making them sustainable within the logic of the public health service ${ }^{12}$.

There is a notable scarcity of studies that evaluate dimensions other than effectiveness ${ }^{16,17}$. The identification of intervening factors in relation to the reach of programs that promote physical activity in Basic Health Care (BHC) allows important reflections that can affect the implementation process.

Reach is one of the dimensions of the RE-AIM tool $^{18}$ and consists of a measure of participation on an individual level. In other words, it considers the absolute, relative and representative number of users who are interested in participating in a program, compared with those considered potentially eligible ${ }^{19}$.

In addition, when considering this dimension from the perspective of the professionals involved in the program, especially with regard to barriers and facilitators, it is of fundamental importance to understand aspects that influence the adherence of users to the intervention. In view of the above, the present study investigated organizational barriers and facilitators to the reach of the VAMOS program in Basic Health Units (BHUs) in Florianópolis, Santa Catarina, Brazil.

\section{METHOD}

An experimental study using a mixed method approach was carried out ${ }^{20}$. The study was conducted in Florianópolis, Santa Catarina, Brazil, specifically, in two BHUs, in the year 2012. The population was composed of elderly BHC users and professionals from the BHU health service. In the year in question, the municipal region had an estimated population of 421,240 inhabitants and 50 BHUs distributed among five Health Districts (Center $=5$ BHUs, Mainland $=12$ BHUs, East $=9$ BHUs, North $=11$ BHUs and South $=13$ BHUs $)^{21}$.

In order to define the BHUs in which VAMOS would be implemented, inclusion criteria were adopted hierarchically, and it was established that the program would only be implemented where all levels agreed to participate. Approval was required from: the Municipal Health Department; the project management in the BHC network; the coordination of the Family Health Support Center (FHSC); the coordination of each Health District; the coordination of the BHUs; and the FHSC Physical Education Professional. 
The professionals involved were: managers or coordinators of programs developed in the $\mathrm{BHC}$ of Florianopolis City Council ( $\mathrm{n}=2$ ), FHSC Physical Education professionals $(n=7)$ and professionals of the BHU health teams, including coordinators $(\mathrm{n}=2)$, upper $(\mathrm{n}=2)$ and middle $(\mathrm{n}=3)$ level health professionals and community health agents (CHA) $(n=13)$.

Elderly persons who had undergone some type of procedure in the $\mathrm{BHU}$ in the six months prior to the start of the study (November 2011 to April 2012) were eligible to participate in VAMOS. To identify such individuals, data from the health information system (or InfoSaúde) of the Municipal Health Department ${ }^{21}$ were consulted. From this information it was possible to quantify the number of elderly persons from the BHUs who were potentially eligible.

The health professionals participated in the VAMOS outreach process and were involved in all stages. Meetings were held about the implementation of the program, and dissemination strategies were developed with the staff of the health teams at each BHU, to invite elderly users to attend a meeting about the program. Among these strategies were: posters placed in the BHU, verbal invitations from professionals during appointments, verbal invitations and distribution of flyers by $\mathrm{CHAs}$ in community centers, churches and during home visits. The health teams publicized the program for a period of 15 to 20 days.

The elderly persons were invited to participate in the first meeting (stage 1 -S1) at a defined date, place and time. This was conducted by a team of researchers from the Universidade Federal de Santa Catarina (UFSC) with the assistance of health teams from the BHUs. VAMOS and how to participate in the program were discussed at the meeting. In order to identify the profile of those interested in participating, an individual assessment was carried out to obtain sociodemographic, clinical, anthropometric and lifestyle data.

However, due to the reduced participation of the elderly in each BHU in S1, the team of researchers with the health teams reformulated the format of the program presentation meeting, and established a new period of dissemination in order to recruit more participants. After final recruitment, two classes were formed (one in each BHU) and the program began.

The VAMOS program is based on the concept of empowerment, following an approach aimed at improving individual skills, identifying barriers that are important to people's lives, and developing strategies to minimize the same ${ }^{14}$.

The group program lasted for 12 consecutive weeks, and involved weekly meetings of approximately 90 minutes, which were conducted by previously trained FHSC Physical Education professionals. At each meeting a topic from the didactic material was presented, available free to the elderly, using the methodology "health education" and behavior change techniques ${ }^{14}$. This program format, aimed at behavior change and developed and tested directly in the health service in Brazil is considered an unprecedented strategy.

The VAMOS meetings were held in the premises of a BHU and in a community space (church). Participation in the meetings was encouraged through positive reinforcement in the form of gifts to the participants and snacks at the end of each meeting to broaden interaction between the group.

During the program (stage 2 - S2), two focus groups were conducted with the Physical Education professionals involved in the study, the first of which occurred one month after the beginning of VAMOS and the other two months after the program began.

A focus group is a form of a collective interview that represents a network of interactions based on communication and seeks to gather information about the understanding of a particular topic ${ }^{22}$. A previously defined script was used and the meetings were conducted by a moderator trained and experienced in the technique, with the aid of two observers. The focal groups had an average duration of 30 minutes and the discourses were recorded and transcribed in full.

At the end of the program, post-intervention evaluations (stage 3 - S3) were performed. A new evaluation of the elderly (identical to S1) and 12 individual interviews (average duration of 15 
minutes) were carried out with: the coordinator of the project management of the Municipal Health Department of Florianópolis, the coordinator of Physical Education of the FHSC, the FHSC Physical Education professionals who did not agree to the application of the program and the professionals from the BHUs that participated in the study, who were BHU coordinators and higher and middle level professionals. In addition to the interviews, three focus groups were conducted, two with the CHAs of each BHU and one with the Physical Education professionals involved in the program.

The reach of the VAMOS program was evaluated using the RE-AIM tool ${ }^{18}$, which aims to evaluate the real impact of public health programs ${ }^{16,18,19}$. To calculate reach, the following formula was used: number of people who participated $\div$ number of eligible persons $\times 100=$ reach. In this study, the reach rate was obtained by the number of elderly people who were willing to participate in VAMOS and who underwent the first evaluation, divided by the number of potentially eligible elderly persons.

The descriptive data were expressed as mean, standard deviation, absolute and relative frequencies. Organizational barriers and facilitators were evaluated through focus group data and interviews using the thematic content analysis technique based on the following phases: pre-analysis, material exploration, interpretation of the statements ${ }^{23,24}$.
The study was approved by the UFSC Ethics Committee on Research Involving Human Beings under process $n^{\circ} 2,387$ and complied with the ethical precepts of Resolution 466/12 of the National Health Council. All the study participants read and signed a Free and Informed Consent Form.

\section{RESULTS}

Two BHUs from Florianópolis participated in this study and agreed to implement the VAMOS program. Of these, one was from the North Health District (BHU 1) and one from the Eastern Health District (BHU 2).

The reach rate of the program is shown in Figure 1.

Of the 297 eligible elderly persons, 30 participated in the first meeting (S1) and, after an extra dissemination period, 21 elderly persons joined, giving a total of 51 participants. BHU 2 of the Eastern Health District had the highest reach rate (20.4\%). Through the first evaluations of the elderly in each BHU, it was possible to identify the profile of the population who were interested in participating in VAMOS (Table 1).

Organizational barriers and facilitators for the reach of VAMOS were subdivided according to the categories identified and the number of occurrences (Chart 1). 
REACH OF VAMOS PROGRAM

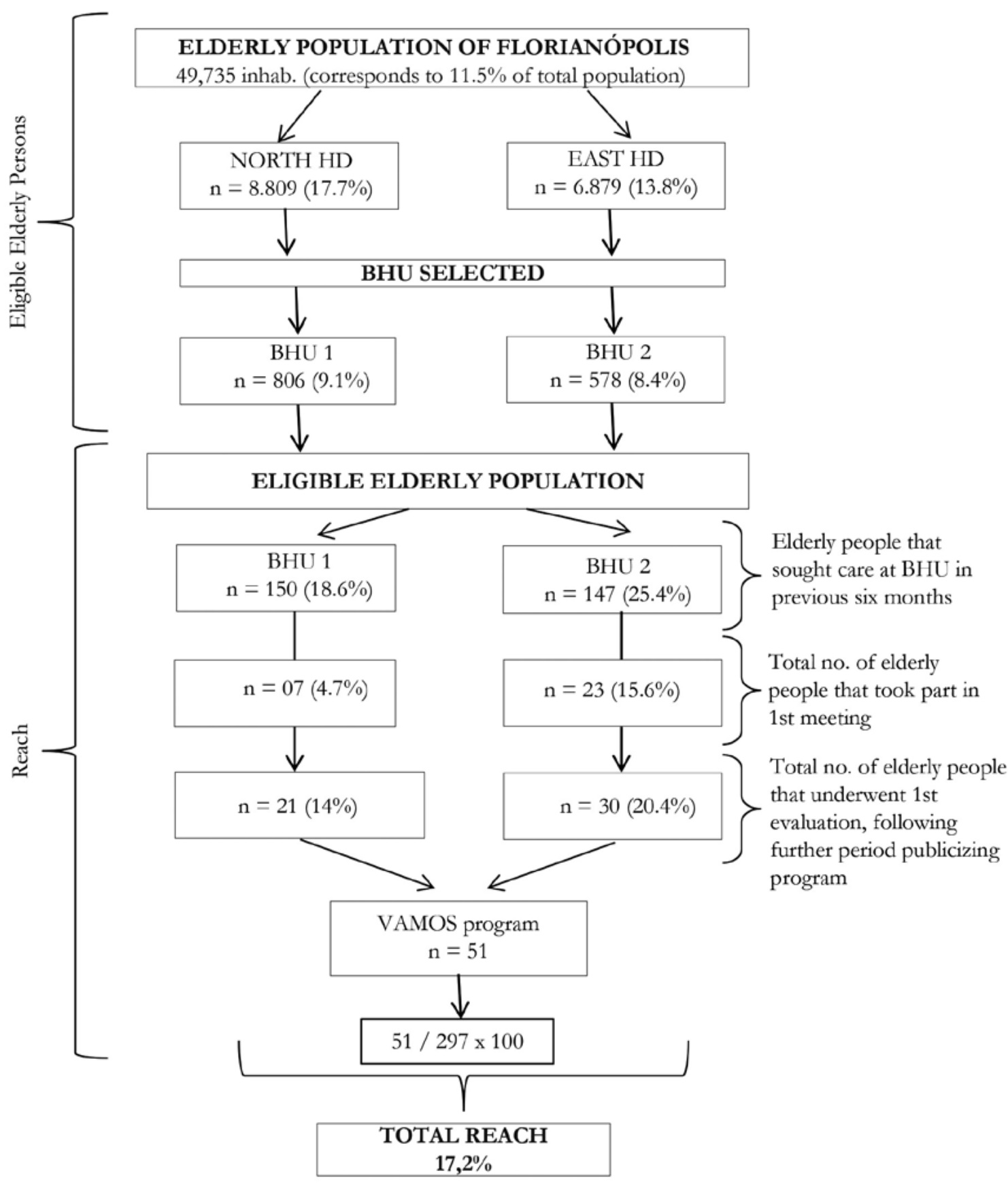

$\mathrm{HD}=$ Health District. BHU $=$ Basic Health Unit.

Figure 1. Populational reach of VAMOS in BHUs. Florianópolis, Santa Catarina, 2012. 
Table 1. Sociodemographic, clinical, anthropometric and lifestyle profile of the elderly, by BHU (S1). Florianópolis, Santa Catarina, 2012.

\begin{tabular}{|c|c|c|}
\hline Sociodemographic Variables & BHU 1 & BHU 2 \\
\hline Age (years) $*(n=37)$ & $69.5( \pm 8.6)$ & $70.1( \pm 7.1)$ \\
\hline \multicolumn{3}{|l|}{ Gender $* *(n=51)$} \\
\hline Female & $12(57.1)$ & $29(96.6)$ \\
\hline Male & $9(42.9)$ & $1(3.4)$ \\
\hline \multicolumn{3}{|l|}{ Schooling** $(n=40)$} \\
\hline Illiterate & $3(13.0)$ & $0(0.0)$ \\
\hline Incomplete Primary & $9(39.0)$ & $11(65.0)$ \\
\hline Complete Secondary & $3(13.0)$ & $3(17.0)$ \\
\hline Complete Higher & $4(18.0)$ & $2(12.0)$ \\
\hline Others & $4(17.0)$ & $1(6.0)$ \\
\hline \multicolumn{3}{|l|}{ Civil Status $* *(n=40)$} \\
\hline Married/Civil Partnership & $17(74.0)$ & $8(47.0)$ \\
\hline Widowed & $2(9.0)$ & $6(35.0)$ \\
\hline Divorced & $4(17.0)$ & $3(18.0)$ \\
\hline \multicolumn{3}{|l|}{ Current Occupation $* *(n=37)$} \\
\hline Retired & $14(66.0)$ & $11(69.0)$ \\
\hline Pensioner & $2(10.0)$ & $3(19.0)$ \\
\hline Paid Labor & $1(5.0)$ & $0(0.0)$ \\
\hline Unpaid Labor & $3(14.0)$ & $0(0.0)$ \\
\hline Others & $1(5.0)$ & $2(12.0)$ \\
\hline \multicolumn{3}{|l|}{ Clinical } \\
\hline \multicolumn{3}{|l|}{ Presence of Disease ${ }^{* *}(n=40)$} \\
\hline Yes & $23(100.0)$ & $16(94.0)$ \\
\hline Not & $0(0.0)$ & $1(6.0)$ \\
\hline \multicolumn{3}{|l|}{ Use of Medications** $(n=40)$} \\
\hline Yes & $20(87.0)$ & $15(88.0)$ \\
\hline Not & $3(13.0)$ & $2(12.0)$ \\
\hline \multicolumn{3}{|l|}{ Anthropometric } \\
\hline Waist Circumference $(\mathrm{cm})^{*}(\mathrm{n}=37)$ & $89.0( \pm 11.4)$ & $93.2( \pm 7.9)$ \\
\hline Body Mass Index $\left(\mathrm{kg} / \mathrm{m}^{2}\right)^{*}(\mathrm{n}=37)$ & $26.8( \pm 0.9)$ & $28.1( \pm 1.1)$ \\
\hline \multicolumn{3}{|l|}{ Lifestyle } \\
\hline Daily MVPA level (minutes)* $(\mathrm{n}=43$ ) & $32.1( \pm 6.1)$ & $36.0( \pm 5.5)$ \\
\hline
\end{tabular}

$*$ Values show mean \pm standard-deviation; $* *$ Data presented as absolute and relative frequency (in brackets); MVPA $=$ moderate/vigorous physical activity. 
Chart 1. Organizational barriers and facilitators for reach of VAMOS program in BHUs of Florianópolis, Santa Catarina, 2012.

\begin{tabular}{|c|c|}
\hline \multicolumn{2}{|c|}{ Reach } \\
\hline Barriers $(n=15)$ & Facilitators $(n=20)$ \\
\hline Lack of support from health teams $(n=9)$ & Recommendation of program $(n=11)$ \\
\hline Lifestyle of the elderly $(\mathrm{n}=7)$ & Includes practical activities $(\mathrm{n}=7)$ \\
\hline Lack of understanding about the program $(n=6)$ & Interest in the program $(n=6)$ \\
\hline $\begin{array}{l}\text { Resistance to the innovative character of the program } \\
(\mathrm{n}=4)\end{array}$ & CHA support $(\mathrm{n}=5)$ \\
\hline Elderly persons participated in other groups $(n=4)$ & Delivery of flyer in BHU ( $\mathrm{n}=5)$ \\
\hline $\begin{array}{l}\text { Program format limits the participation of illiterate } \\
\text { people }(n=4)\end{array}$ & $\begin{array}{l}\text { Involvement of health teams in publicizing program } \\
(\mathrm{n}=4)\end{array}$ \\
\hline Administrative problems in $\mathrm{BHU}(\mathrm{n}=3)$ & Informed about program face to face $(n=4)$ \\
\hline Program timetable $(\mathrm{n}=2)$ & Longer period publicizing program $(n=4)$ \\
\hline Overlooks territorial needs $(\mathrm{n}=2)$ & Diversification of age group $(n=3)$ \\
\hline Short period publicizing program $(n=2)$ & Printed didactic material $(\mathrm{n}=3)$ \\
\hline Seasonal nature $(n=2)$ & Physical structure in or near BHU $(n=2)$ \\
\hline Physical distance $(\mathrm{n}=2)$ & PEP known to community $(\mathrm{n}=2)$ \\
\hline Community resistant to program $(\mathrm{n}=1)$ & Publicized in strategic locations $(n=2)$ \\
\hline Lack of communication $(n=1)$ & Publicized through former participants $(n=2)$ \\
\hline Program for restricted population $(n=1)$ & Flexible program $(\mathrm{n}=1)$ \\
\hline & Offer program to health teams $(\mathrm{n}=1)$ \\
\hline & Meet the needs of the participants $(n=1)$ \\
\hline & Permanent publicity of program $(n=1)$ \\
\hline & Publicizing of program on radio $(\mathrm{n}=1)$ \\
\hline & Program has a beginning, middle and end $(n=1)$ \\
\hline
\end{tabular}

$\mathrm{CHA}=$ Community Health Agent; $\mathrm{BHU}=$ Basic Health Unit; PEP = Physical Education Professional; $\mathrm{n}=$ number of occurrences .

\section{DISCUSSION}

To understand the results, the discussion focuses on the three topics investigated: population reach, organizational barriers and organizational facilitators, emphasizing the main findings. It should be pointed out that, given the richness of the discourses analyzed, the sections of the speech with greater emphasis will be presented in order to broaden the understanding of the analyzed variables.

\section{Population reach of VAMOS}

The results of the study show a participation rate of $17.2 \%$, higher than that found in the Squarcine study ${ }^{25}$, which found a rate of $1.6 \%$. The low reach of existing programs has worried researchers ${ }^{12,14}$. Despite evidence in literature ${ }^{26,27}$ on the effectiveness of physical activity promotion programs, little progress has been made in finding new participants, failing to serve or reach a large portion of the population.

A study ${ }^{28}$ suggests strategies, considered facilitators, to participate in behavior change programs, minimizing possible barriers and maximizing reach. Such strategies consist of locally accessible programs that allow quick and easy access, such as convenient, small-size socializing interventions, as well as informative websites, online programs, and integrative strategies for healthy behaviors in daily life. 
Specific cell phone apps also represent an effective strategy and can be used by health professionals to promote the practice of physical activity ${ }^{29}$. Such technologies have the potential to significantly impact public health ${ }^{30,31}$.

According to Mathews et al..$^{32}$, physical activity promotion strategies should address the modifiable determinants of physical activity, such as improving self-efficacy and knowledge about adequate fitness activity and recommended strategies for achieving the same, facilitating the achievement of goals, and improving social support through peer support and group-based activities.

From this it can be inferred that it is not enough to be effective, a program must also be attractive, so that reach is enhanced and a large part of the population benefits.

\section{Organizational barriers to VAMOS reach}

One barrier was the lack of support from the health teams. This is partly because the team believed it was not a BHU program, but rather something connected to the University. The professionals of the $\mathrm{BHU}$ were slow to incorporate the publicizing of the program in their daily routine of activities. “... the (health team) wasn't obliged to do it. So it wasn't seen as a group from the unit, and so the team wasn't responsible for it ... "(CHA BHU 2).

Another barrier mentioned related to the lifestyle of the elderly. In the view of some professionals, they generally prefer to spend most of their time at home, making it difficult for them to become involved in community group activities: "[...] I think it was difficult because they're at home a lot, aren't they? They don't go out much. For most of the elderly people it's their children who do things, right?" (MLP BHU 2).

A lack of understanding about the program was another barrier. As a cultural issue, health teams had limited understanding of what a behavior change program is, and the lack of understanding among the professionals involved made the recruitment of participants slower. "[...] people still don't have a culture of talking about physical activity in theoretical groups, so often the teams didn't understand [...]" (PEP 1). During the presentation of VAMOS to the health teams, according to the same individual, the objectives and format of the program were not clear: "[...] so much so that the teams often did not understand [...]" (PEP 1).

A lack of understanding of VAMOS may have influenced the ability of health care staff to invite elderly people to participate, affecting reach. However, this view was not in line with the answers given, as professionals referred to the program as attractive and innovative compared to other models of programs in BHC. The CHA criticized the impact of specific actions of Physical Education that routinely apply in the network:

"[...] these innovations that the program brings, "what is it to be active?" because we work hard with, say, intermittent Physical Education actions, and do not reflect on what it is to be active in life. Thinking that you just go to the gym, do an hour, you're active. So for me, this awareness of being active on a daily basis is a great innovation of the program [...].” (G1).

Even with professionals realizing that the innovative character of VAMOS is an improvement over the current proposed program models, this characteristic was initially seen by the elderly as a barrier. "... They (the elderly) have a certain difficulty with everything that is new ... they are afraid and then, when inviting them to do something new, they are frightened, just like a cbild, right? ... they do not know what will happen." (CHA BHU 1).

In terms of a general analysis of the barriers, it should be noted that VAMOS was considered to have an innovative format for a program for the promotion of physical activity. It is very different to what the population is accustomed to, and initially there was resistance from the elderly, mainly because they are not used to participating in theoretical physical activity promotion programs.

According to literature, traditional programs of physical activity are culturally more attractive, since they are based on a framework of eminently practical activities $^{33}$. Therefore, the identification of barriers that limit the applicability of behavior change programs is an important way of optimizing the actions performed. 


\section{Organizational facilitators of VAMOS reach}

In relation to facilitating factors, several factors that can lead to the maximization of reach among the target population by BHC professionals were identified. Some of these are directly related to dissemination strategies, others to the attitudes of professionals and, finally, to the format of the program.

One frequently recurring facilitator was the recommendation of VAMOS by professionals. It is understood that if these professionals, in their different actions within the BHU, recommend the program, its dissemination is maximized, as it is not only diffusion by one professional or another, but by of all of them, as part of a team effort. "For sure [...]." (CHA BHU 1; ULP BHU 2); "I would recommend it [...].” (CHA BHU 2).

The insertion of practical activities, especially dance, was also considered an interesting strategy for attracting the elderly to the program by the BHC professionals. "But ifyou organize a dance class, then they'll come." (CHA BHU 2); "If it was like this, it there's going to be a band when we start exercising, they'll come, I guarantee they like to dance." (CHA BHU 2).

Interest in the program is an essential facilitator. If the health team has no interest in implementing it, then implementation will not be successful. This interest is shown below, where the coordinator reports a feeling of sadness at not being able to become more involved in the process: "[...] I am sad because I could not get involved, but it's like I said, the health center is more disorganized in recent years, we've been commenting on it [...]." (Coordination BHU 2).

The support of the CHAs was fundamental to the process of attracting the elderly. In this sense, a proposal was launched by the CHAs: applying VAMOS among themselves, even before recruiting users. This proposal would increase the understanding of the program by these professionals, as it would allow them to adopt the practice of physical activity. Getting to know and experiencing what the program is about, they would have the opportunity to enjoy its benefits, positively influencing its dissemination: "[...] It would be good if the team could do the program ..."
(CHA BHU 1); "... but in itself the program motivated the employees to be more active, and we ended up passing this enthusiasm on to the girls." (Other BHU professionals).

The adaptation and flexibility of the program in the context of BHC was cited as a facilitator. Set programs without the possibility of change are often created, and their application is practically unfeasible. In this sense, the need to design a program with a flexible format that adapts to context was identified, as each reality is unique and each group has its needs. "[...] one thing that made it easier (the recruiting) was that they could not only join at the start (flexible program), they could join the next week, with each of them telling the others about it [...]." (Coordination BHU 1).

In addition, the Physical Education professionals who applied VAMOS warned of the need for adjustments in the program, considering the profile of the majority of Brazilian elderly persons: “[...] Our elderly people do not like to read, it has to be modified (referring to the textbook used as a base) [...]. "(PEP 1); “[...] Lessons can't be so theoretical [...]". (PEP 2). According to the professionals, irrespective of the fact that it is an educational program, VAMOS should have practical activities, making it more attractive.

Another interesting aspect in relation to facilitating the recruitment of participants that was suggested is that VAMOS should not be limited to the elderly, but also to younger people, mainly because it is a behavior change program " [...] I would be a little reluctant to leave it only for the elderly, broadening it more to other age groups I think. (there would be demand) [...]. (Coordination BHU 1). But it is worth mentioning that even in programs that are open to the general population, the highest adherence in activities is among people over 50 , who are usually female ${ }^{34}$.

Therefore, reach can be facilitated if the program to be implemented is designed through considering its real world feasibility. Flexibility is essential, so that the program can adjust to the practical environment ${ }^{33}$. In other words, the intervention must be adaptable, something conceived in VAMOS from the outset.

The present study did not include a detailed description of the sociodemographic and behavioral characteristics of the target population, a fact that 
limits representative analyzes to elucidate the profile of the potential users of the program.

This study extrapolates the laboratory context, as it was developed in the "real world". The data strengthens the external validity of the study, as the health professionals themselves described the organizational barriers and facilitators that interfered in the process of recruiting the elderly to the VAMOS program. In addition, two different contexts were presented, reach by Health District and by BHU.

\section{CONCLUSION}

The present study provides important research that can contribute to the process of evaluating programs

\section{REFERENCES}

1. Brasil. Ministério da Saúde. Vigitel Brasil 2016. Vigilância de fatores de risco e proteção para doenças crônicas por inquérito telefônico: estimativas sobre frequência e distribuição sociodemográfica de fatores de risco e proteção para doenças crônicas nas capitais dos 26 estados brasileiros e no Distrito Federal em 2016. Brasília, DF: MS; 2017.

2. World Health Organization. World health statistics 2017: monitoring health for the SDGs, sustainable development goals. Genebra: WHO; 2017.

3. United States. Department of Health and Human Services. Physical Activity Guidelines for Americans, 2nd edition. Washington, DC: U.S. Department of Health and Human Services; 2018.

4. Murphy MM, Unwin N, Samuels TA, Hassell TA, Bishop L, Guell C. Evaluating policy responses to noncommunicable diseases in seven Caribbean countries: challenges to addressing unhealthy diets and physical inactivity. Rev Panam Salud Publica. 2018;42(e174):1-8.

5. Brasil. Ministério da Saúde, Secretaria de Vigilância em Saúde, Secretaria de Atenção à Saúde. Política Nacional de Promoção da Saúde: PNPS: revisão da Portaria MS/GM no 687 de 30 de março de 2006. Secretaria de Vigilância em Saúde Ministério da Saúde. Brasília, 2015 in Primary Health Care, aiming to reach and benefit a wider public with health promotion strategies.

The implementation of the VAMOS program showed that the organizational strategies used need to be improved to widen reach within the Unified Health System. However, it was observed that as a behavior change program to promote an active and healthy lifestyle, VAMOS has the potential to be incorporated as part of public policy in the process of care and promotion of the health of Basic Health Care users.

The program format and strategies of recruitment of the target population are being improved in order to enhance the VAMOS program and minimize the barriers highlighted in this study.

6. Malta DC, Moraes Neto OL, Silva MMA, Rocha D, Castro AM, Reis AAC, et al. Política Nacional de Promoção da Saúde (PNPS): capítulos de uma caminhada ainda em construção. Ciênc Saúde Colet. 2016;21(6):1683-94.

7. Santos SFS, Benedetti TRB, Medeiros TF, Freitas CLR, Sousa TF, Costa JLR. The work of physical education professionals in Family Health Support Centers (NASF): a national survey. Rev Bras Cineantropom Desempenho Hum. 2015;17(6):693-703.

8. Lovato NS, Loch MR, González AD, Lopes MLS. Assiduidade a programas de atividade física oferecidas por Unidades Básicas de Saúde: o discurso de participantes muito e pouco assíduos. Rev Bras Ativ Fis Saúde. 2015;20(2):184-92.

9. Steffl M, Bohannon RW, Sontakova L, Tufano JJ, Shiells K, Holmerova I. Relationship between sarcopenia and physical activity in older people: a systematic review and meta-analysis. Clin Interv Aging. 2017;17(12):835-45.

10. Daskalopoulou C, Stubbs B, Kralj C, Koukounari A, Prince M, Prina AM. Physical activity and healthy ageing: a systematic review and meta-analysis of longitudinal cohort studies. Ageing Res Rev. 2017;38:6-17. 
11. Sáez de Asteasu ML, Martínez-Velilla N, ZambomFerraresi F, Casas-Herrero A, Izquierdo M. Role of physical exercise on cognitive function in healthy older adults: a systematic review of randomized clinical trials. Ageing Res Rev. 2017;37:117-34.

12. Benedetti TRB, Schwingel A, Gomez LSR, Chodzko-Zajko W. Programa "VAMOS" (Vida Ativa Melhorando a Saúde): da concepção aos primeiros resultados. Rev Bras Cineantropom Desempenho Hum. 2012;14(6):723-37.

13. Bandura A. Social Foundations of Thought and Action: a social cognitive theory. Englewood Cliffs: Prentice-Hall; 1986.

14. Benedetti TRB, Manta SW, Gomez LSR, Rech CR. Logical model of a behavior change program for community intervention - Active Life Improving Health - VAMOS. Rev Bras Ativ Fis Saúde. 2017;22(3):309-13.

15. Tonosaki LMD, Rech CR, Mazo GZ, Antunes GA, Benedetti TRB. Barreiras e facilitadores para a participação em um programa de mudança de comportamento: análise de grupos focais. Rev Bras Ciênc Esporte. 2018;40(2):138-45.

16. Brito FA, Benedetti TRB, Tomicki C, Konrad LM, Sandreschi PF, Manta SW, et al. Translation and adaptation of the RE-AIM Check List for Brazilian reality. Rev Bras Ativ Fís Saúde. 2018;23:1-8.

17. Forman J, Heisler M, Damschroder LJ, Kaselitz E, Kerr EA. Development and application of the REAIM Quest mixed methods framework for program evaluation. Prev Med Rep. 2017;6:322-8.

18. Glasgow RE, Vogt TM, Boles SM. Evaluating the public health impact of health promotion interventions: the RE-AIM framework. Am J Public Health. 1999;89(9):1322-7.

19. Almeida FA, Brito FA, Estabrooks PA. Modelo REAIM: Tradução e adaptação cultural para o Brasil. REFACS (online). 2013;1(1):6-16.

20. Borges RA. Programa de promoção de atividade física no SUS: barreiras e facilitadores organizacionais [Dissertação]. Florianópolis: Universidade Federal de Santa Catarina, Programa de Pós-Graduação em Educação Física; 2014.

21. Prefeitura Municipal de Florianópolis. Sistemas de Informação - InfoSaúde. Secretaria Municipal de Saúde [Internet]. Florianópolis: PMF; 2013. [acesso em 15 ago. 2013]. Disponível em: http://www.pmf. sc.gov.br/entidades/saude/.
22. Gatti BA. Grupo focal na pesquisa em ciências sociais e humanas. Brasília, DF: Liber Livro; 2012.

23. Bardin L. Análise de conteúdo. São Paulo: Edições 70 Brasil; 2011.

24. Minayo MCS. O desafio do conhecimento. Pesquisa qualitativa em saúde. São Paulo: Hucitec Editora; 2014.

25. Squarcine CFR. Programa de exercícios físicos para pessoas com hipertensão arterial de Jequié-BA: alcance, adesão e efetividade [Tese]. Florianópolis: Universidade Federal de Santa Catarina, Programa de Pós-Graduação em Educação Física; 2016.

26. Meurer ST, Lopes ACS, Almeida FA, Mendonça RD, Benedetti TRB. Effectiveness of the VAMOS Strategy for Increasing Physical Activity and Healthy Dietary Habits: a randomized controlled community trial. Health Educ Behav. 2019;46(3):406-16.

27. Gerage AM, Benedetti TRB, Ritti-Dias RM, dos Santos ACO, de Souza BCC, Almeida FA. Effectiveness of a behavior change program on physical activity and eating habits in patients with hypertension: a randomized controlled trial. J Aging Phys Act. 2017;14(12):943-52.

28. Kelly S, Martin S, Kuhn I, Cowan A, Brayne C, Lafortune L. Barriers and facilitators to the uptake and maintenance of healthy behaviours by people at mid-life: a rapid systematic review. PLoS ONE. 2016;11(1):1-26.

29. Sun L, Wang Y, Wu Y. Facilitators and barriers to using physical activity smartphone apps among Chinese patients with chronic diseases. BMC Med Inform Decis Mak. 2017;17(44):1-10.

30. Weiss D, Rydland HT, Øversveen O, Jensen MR, Solhaug S, Krokstad S. Innovative technologies and social inequalities in health: a scoping review of the literature. PLoS ONE. 2018;13(4):1-20.

31. Sullivan NA, Lachman ME. Behavior change with fitness technology in sedentary adults: a review of the evidence for increasing physical activity. Front Public Health. 2017;4(289):1-16.

32. Mathews E, Lakshmi JK, Trankappan KR. Perceptions of barriers and facilitators in physical activity participation among women in Thiruvananthapuram City, India. Glob Health Promot. 2016;23(4):27-36.

33. Josyula LK, Lyle RM. Barriers in the implementation of a physical activity intervention in primary care settings: lessons learned. Health Promot Pract. 2013;14(1):81-7.

34. Bonfim MR, Costa JLR, Monteiro HL. Ações de educação física na saúde coletiva brasileira: expectativas versus evidências. Rev Bras Ativ Fis Saúde. 2012;17(3):167-73. 